\title{
Reaction of Hydroxyfullerene with Metal Salts: A Route to Remediation and Immobilization
}

\author{
Robin Anderson and Andrew R. Barron* \\ Department of Chemistry and Center for Nanoscale Science and Technology, \\ Rice University, Houston, Texas 77005, USA
}

Supplementary Materials 
Figure S1. Representative SEM image of Fe-cross linked fullerenol agglomerates formed from the reaction of $\mathrm{Fe}\left(\mathrm{NO}_{3}\right)_{3}$ and $\mathrm{C}_{60}(\mathrm{OH})_{\mathrm{n}}$ in aqueous solution.

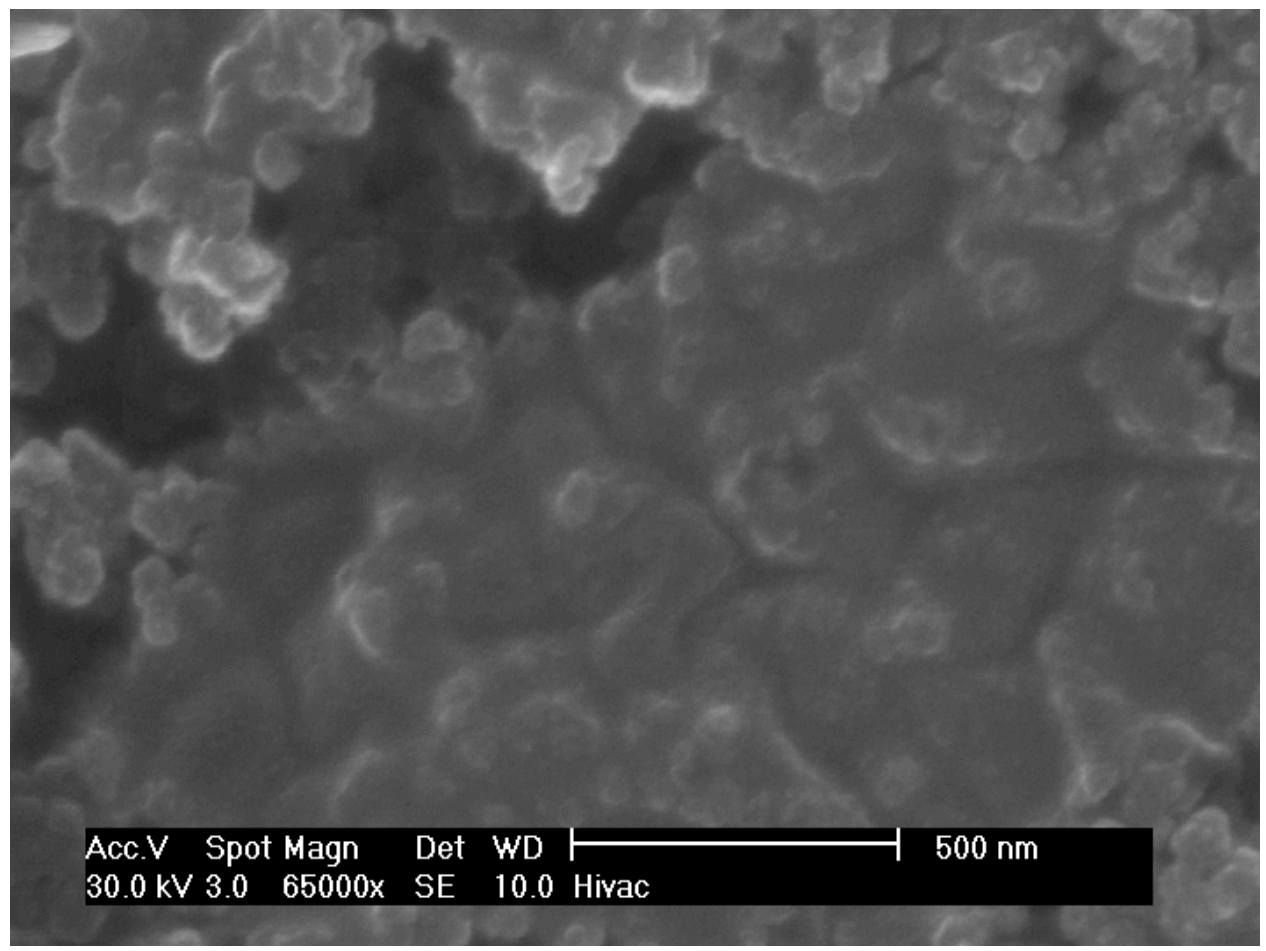


Figure S2. Representative TEM image of Fe-cross linked fullerenol agglomerates formed from the reaction of $\mathrm{Fe}\left(\mathrm{NO}_{3}\right)_{3}$ and $\mathrm{C}_{60}(\mathrm{OH})_{\mathrm{n}}$ in aqueous solution.

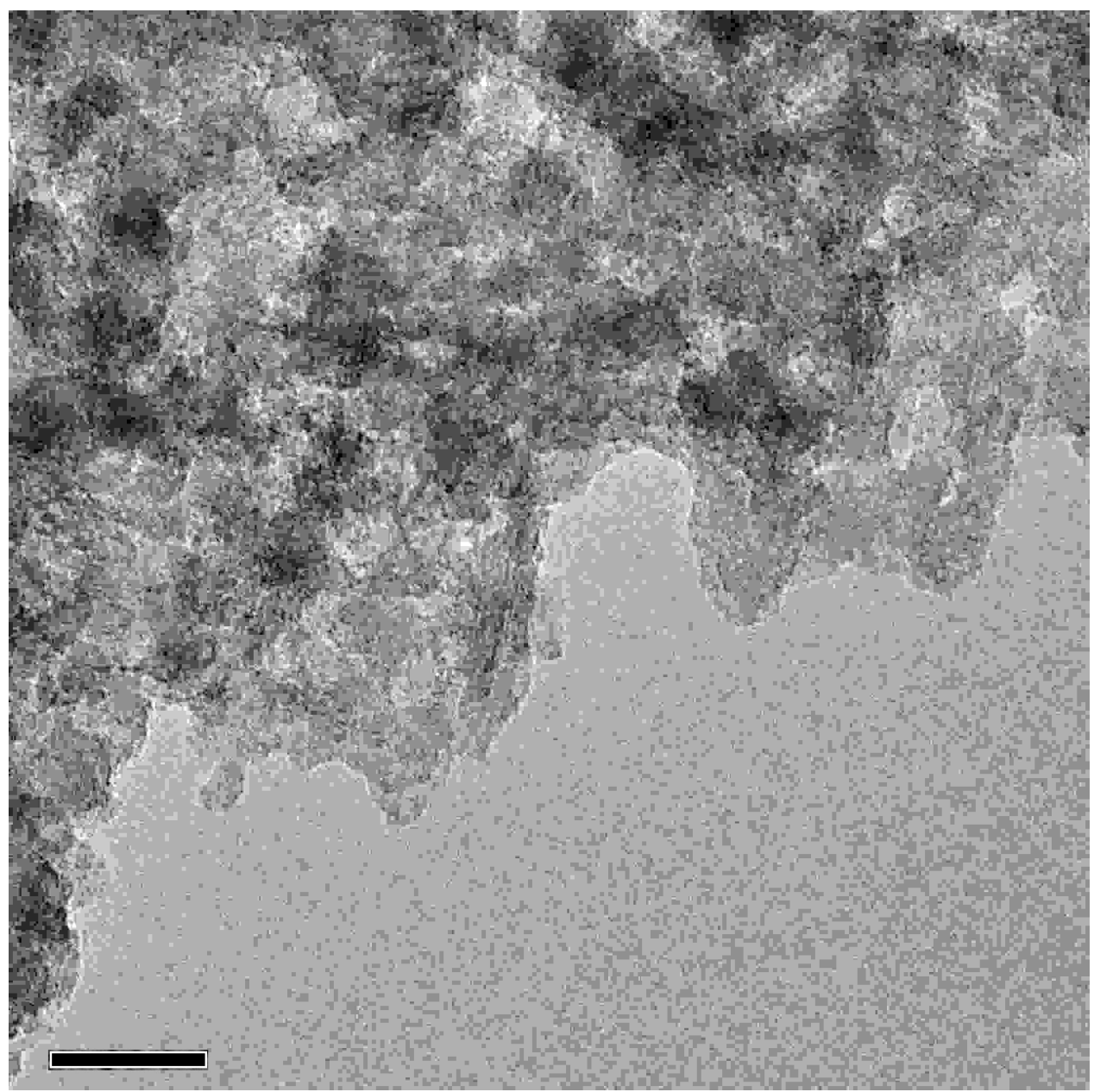


Figure S3. UV-visible spectra of (a) $\mathrm{Fe}\left(\mathrm{NO}_{3}\right)_{3}(50 \mathrm{mM})$ in water, (b) $\mathrm{C}_{60}(\mathrm{OH})_{\mathrm{n}}(50 \mathrm{mM})$ in water, and (c) soluble fraction after reaction between $\mathrm{Fe}\left(\mathrm{NO}_{3}\right)_{3}$ and $\mathrm{C}_{60}(\mathrm{OH})_{\mathrm{n}}$ in water.

(a)

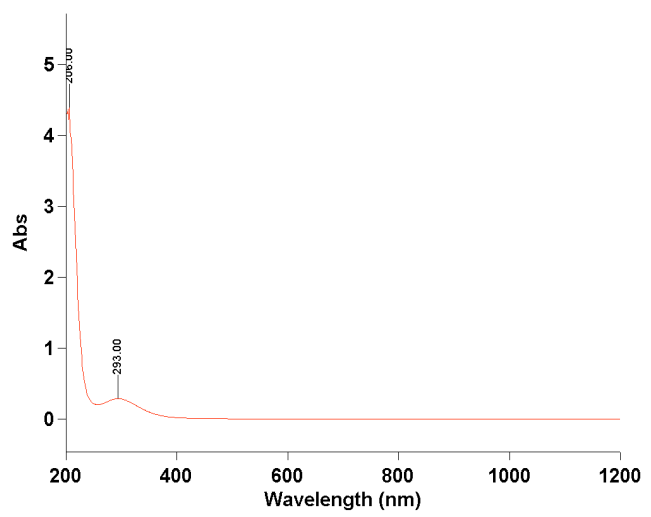

(b)

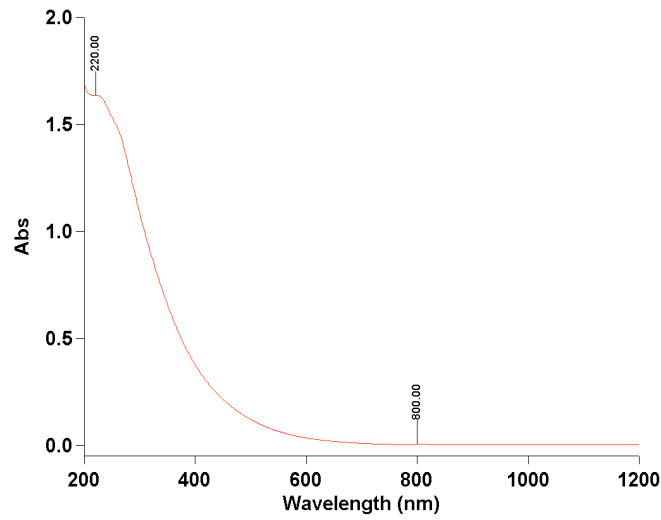

(c)

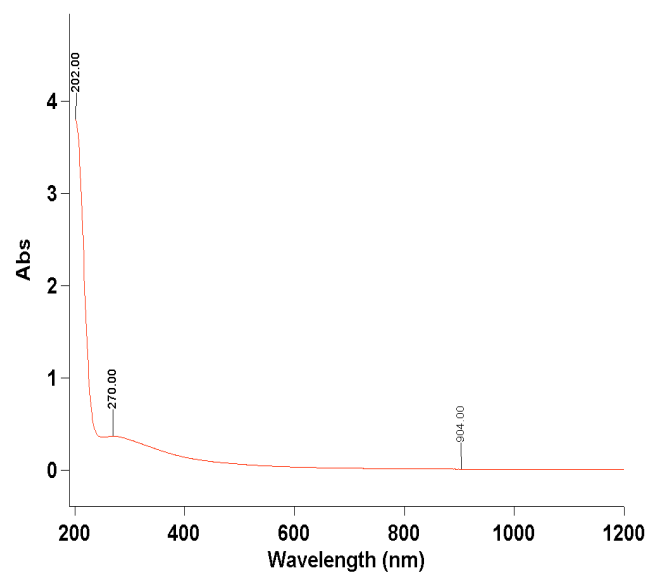


Figure S4. The C 1s (a) and Fe 2p (b) X-ray photoelectron spectral components of fullerenol (blue line) and the product from the reaction of $\mathrm{Fe}\left(\mathrm{NO}_{3}\right)_{3}$ and $\mathrm{C}_{60}(\mathrm{OH})_{\mathrm{n}}$ (red line).

(a)

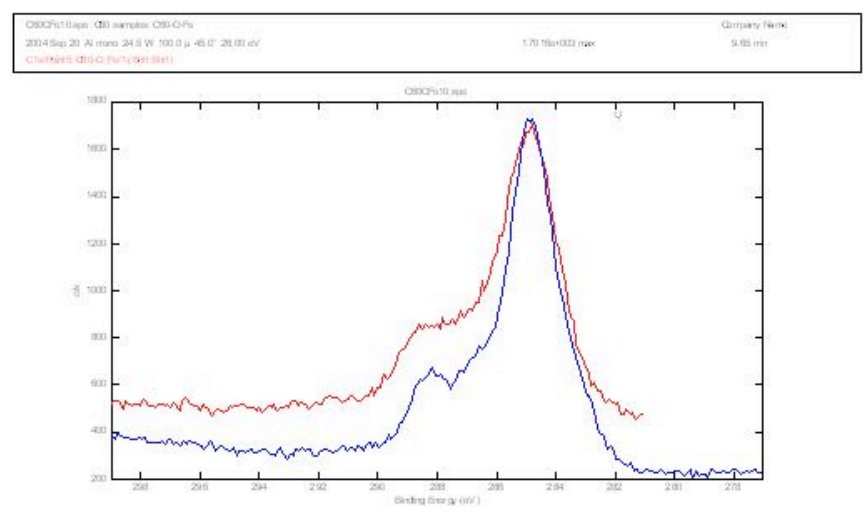

(b)

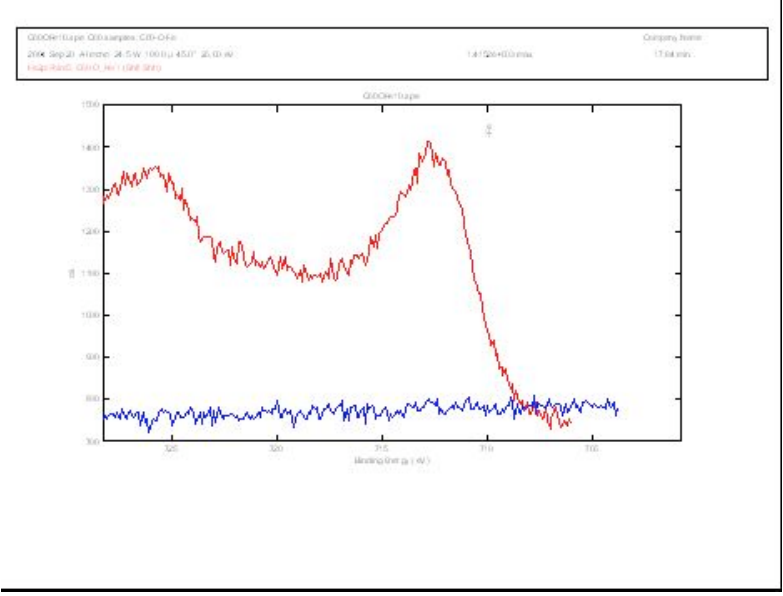


Figure S5. Computer generated structures of $\left[\mathrm{Fe}\left(\mathrm{C}_{60} \mathrm{O}_{2}\right)_{2}\right]$ unit, showing the steric accessibility of the cross-linked unit. Atoms are color coded as follows: carbon (grey), oxygen (red), and iron (green).

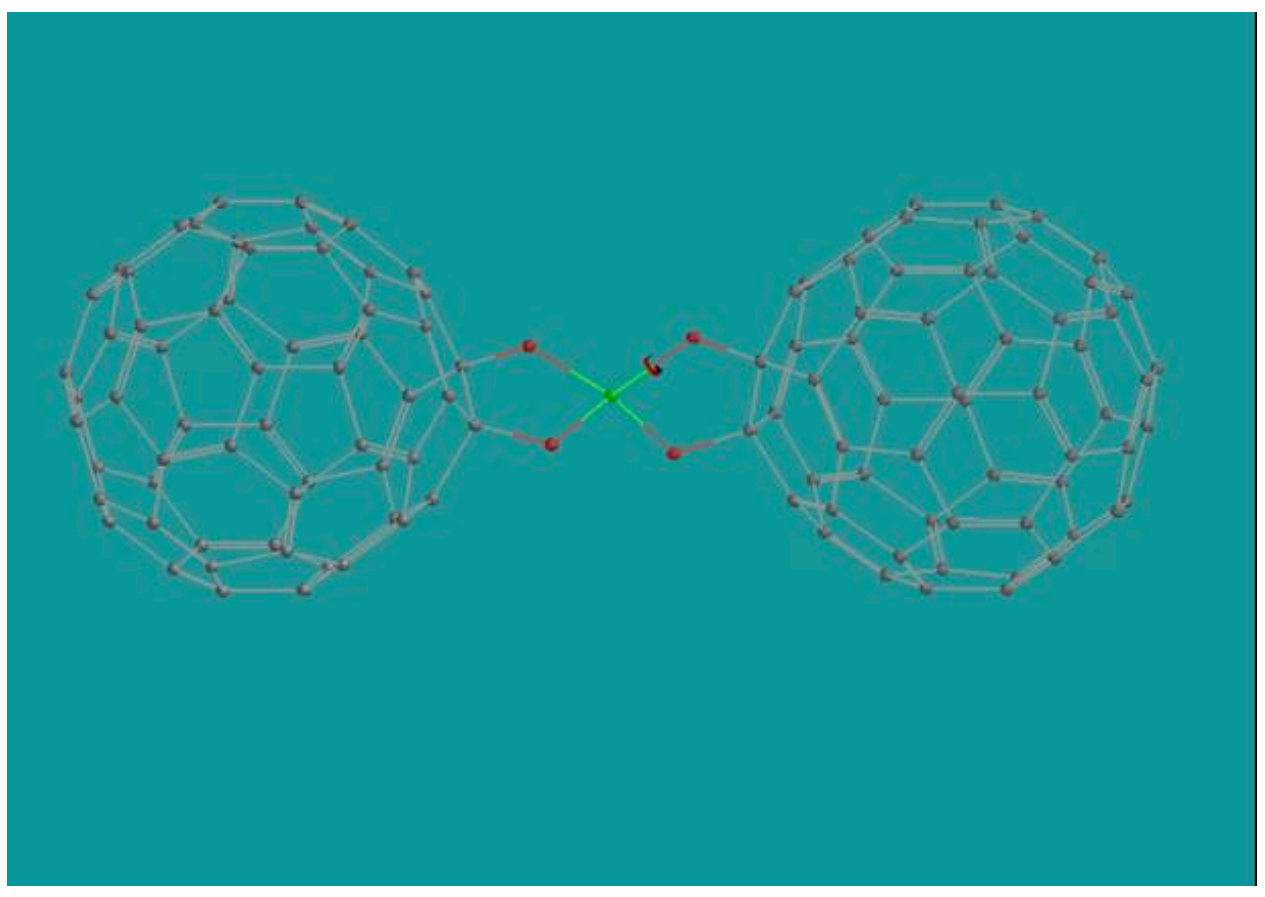


Figure S6. Computer generated structures of $\left[\mathrm{Fe}\left(\mathrm{C}_{60} \mathrm{O}_{2}\right)_{3}\right]$ unit, showing the steric accessibility of the cross-linked unit. Atoms are color coded as follows: carbon (grey), oxygen (red), and iron (green).

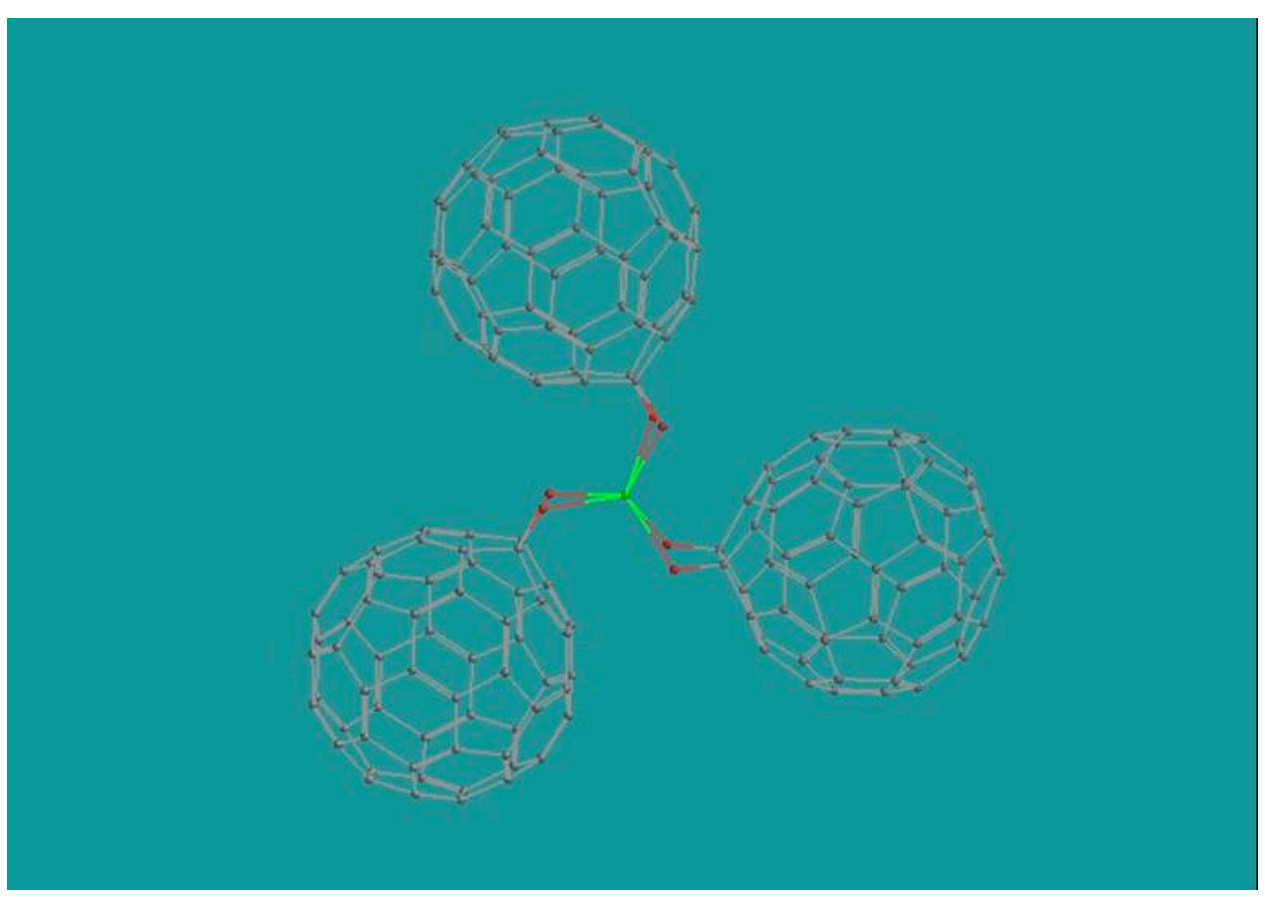


Figure S7. AFM image of Fe-fullerenol showing the particulate nature of the aggregates.

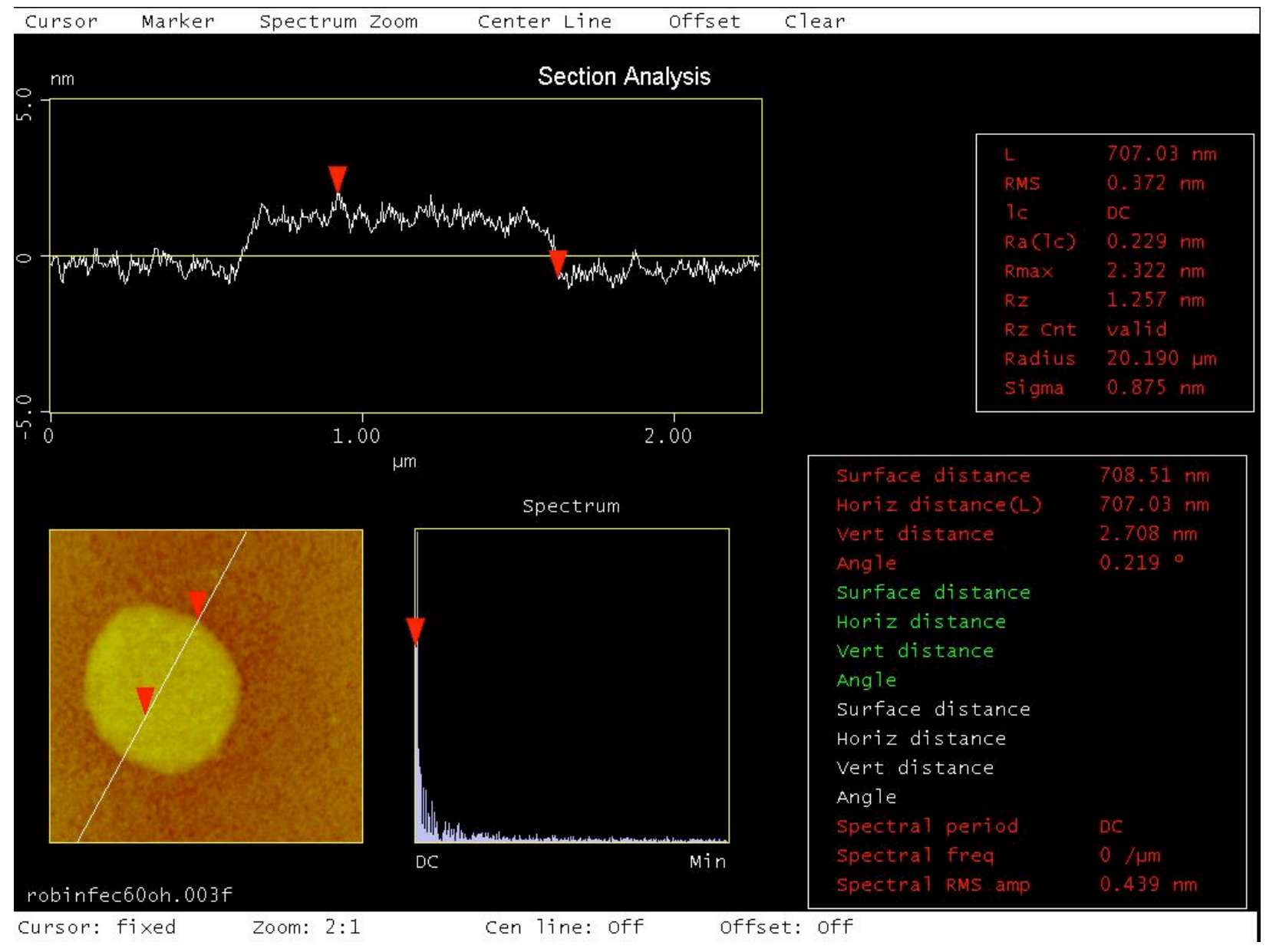

